\title{
An asymptomatic radiology finding with surgical indication Kaushik Saha, ${ }^{a *}$ Debraj Jash, ${ }^{a}$ Malay Kr. Maikap ${ }^{a}$ \\ ${ }^{a}$ NRS Medical College and Hospital, Kolkata, West Bengal, India
}

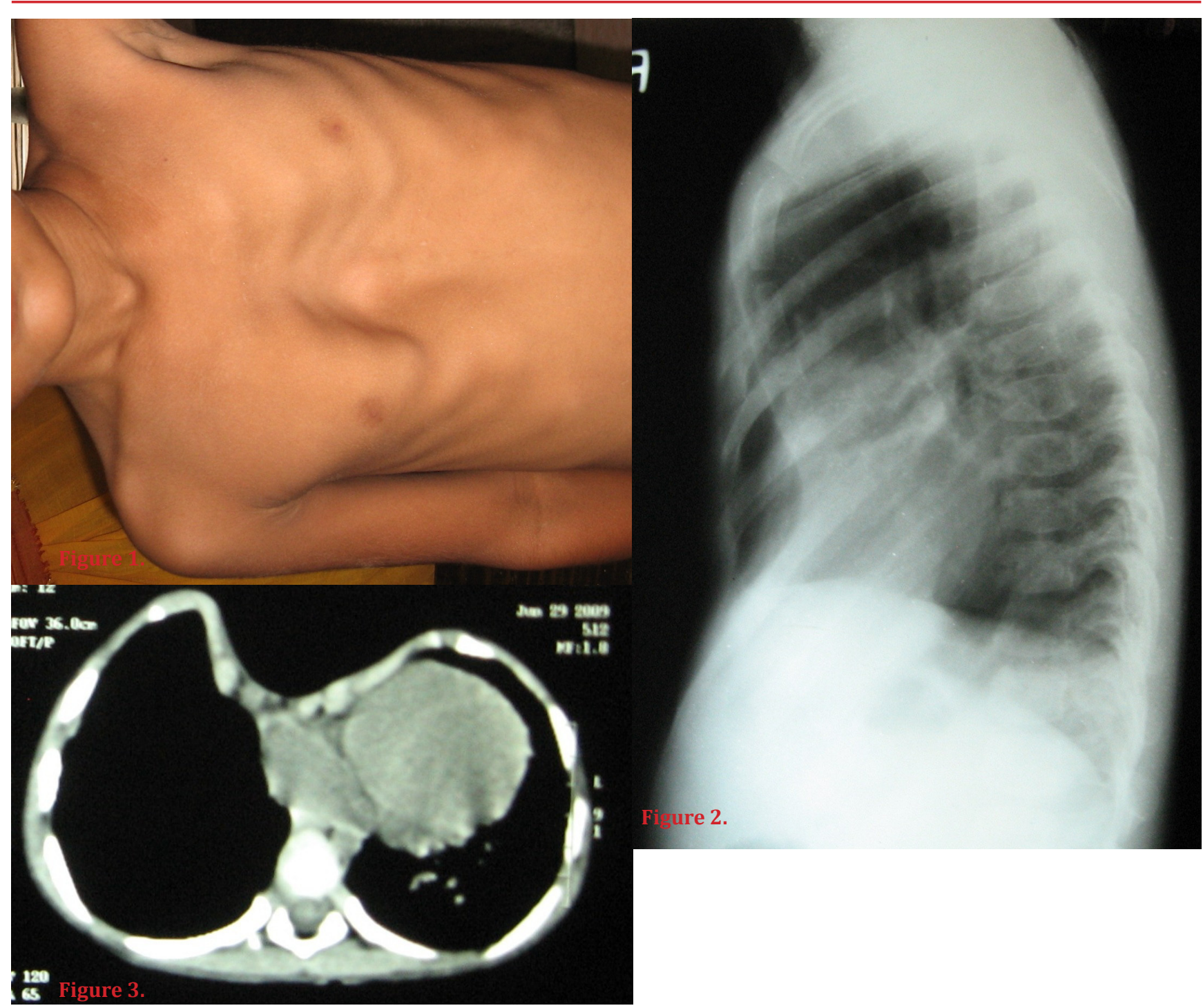

\section{DOI Name}

10.3126/jaim.v1i2.6529

\section{Keywords}

pulmonary, chest wall

\section{Citation}

Saha K, Jash D, Maikap MK. An Asymptomatic Radiology finding with Surgical Indication. Journal of CASE

Advances in Internal Medicine 2012;01(02):68.

A 10 year old boy came to our chest clinic for preanaesthetic check-up before appendicectomy with a chest $x$-ray (CXR) PA view. He had no respiratory complain. We thoroughly examine the boy includ-

\section{* Corresponding author}

Department of Pulmonary Medicine,

NRS Medical College and Hospital, 138, AJC Bose Road,

Kolkata, West Bengal, India.

Email address - doctorkaushiksaha@gmail.com
Answer on page 72 


\section{CONCLUSION}

Patients with upper limb anomalies and cardiac diseases should be evaluated further to rule out HOS. Familial screening should be done. Though genetic diagnosis may not always be possible in resource poor settings like ours howeverearly diagnosis and intervention as required will definitely help to prevent the possible complications in such patients.

\section{ACKNOWLEDGEMENT}

Author is grateful for Dr. Prakash Thapa, Lecturer, Department of Psychiatry, Manipal College of Medical Sceinces, Pokhara, Nepal.

\section{REFERENCES}

1. Holt M, Oram S. Familial heart disease with skeletal malformations. Br Heart J 1960;22:236-4.

2. Warnes CA, Williams RG, Bashore TM, et al. ACC/AHA 2008 Guidelines for the Management of Adults with Congenital Heart Disease: Executive Summary: a report of the American College of Cardiology/American Heart Association Task Force on Practice Guidelines (writing committee to develop guidelines for the management of adults with congenital heart disease). Circulation 2008;118:2395-451.

3. McDermott DA, Hatcher CJ, Basson CT. Atrial Fibrillation and Other Clinical Manifestations of Altered TBX5 Dosage in Typical Holt-Oram Syndrome. Circ Res 2008;103:e96.

4. Basson CT, Huang T, Lin RC, et al. Different TBX5 interactions in heart and limb defined by Holt-Oram syndrome mutations. Proc Natl Acad Sci U S A 1999;96:2919-24.

5. Basson CT, Cowley GS, Solomon SD, et al. The clinical and genetic spectrum of the Holt-Oram syndrome (heart-hand syndrome). $N$ Engl J Med 1994;330:885-91.
6. Garavelli L, De Brasi D, Verri R, et al. Holt-Oram syndrome associated with anomalies of the feet. Am J Med Genet A 2008;146:1185-9.

7. Basson CT, Solomon SD, Weissman B, et al. Genetic heterogeneity of heart-hand syndromes. Circulation 1995;91:1326-9.

8. Cerbai E, Sartiani L. Holt-oram syndrome and atrial fibrillation: opening the (T)-box. Circ Res 2008; 102:1304-6.

9. Postma AV, van de Meerakker JBA, Mathijssen IB, et al. A Gain-of-function TBX5 mutation is associated with atypical Holt-Oram syndrome and paroxysmal atrial fibrillation. Circ Res 2008;102:1433-42.

10. Pete B, Harmath A, Szigeti Z, et al. Holt-Oram syndrome: genetic counseling and diagnosis with prenatal ultrasonography. Orv Hetil 2007;148:2173-6.

11. Sunagawa S, Kikuchi A, Sano Y, et al. Prenatal diagnosis of HoltOram syndrome: role of 3-D ultrasonography. Congenit Anom (Kyoto) 2009;49:38-41.

12. He J, McDermott DA, Song Y, et al. Preimplantation genetic diagnosis of human congenital heart malformation and Holt-Oram syndrome. Am J Med Genet 2004;126:93-8.

\section{ANSWER}

Inspection of chest shows inward depression of chest producing sunken in and caved appearance consistent with the diagnosis of pectus excavatum (Figure 1). Lateral CXR shows inward displacement of sternum with ribs seen anterior to sternum, suggests the diagnosis of pectus excavatum (Figure 2). CT scan thorax shows inward displacement of sternum compressing the heart, confirms the diagnosis of severe pectus excavatum with surgical indication (Figure 3 ).

Pectus excavatum is characterized by inward displacement of the sternum, creating a depression in the chest. Classification of pectus excavatum is categorized according to severity (mild, moderate, or severe) base on radiological criteria. The CT scan is used to ascertain the severity of the deformity, by determining the Haller index: a ratio of the measure of the transverse diameter of the chest, divided by the sagital measure of the distance from the sternum to the vertebral body. The Haller index should be obtained at the deepest point of the deformity. Haller index between 2 and 3.2 is considered a mild deformity; between 3.2 and 3.5 is moderate and 3.5 or above is a severe deformity. ${ }^{1}$ Both moderate and severe deformities can be considered candidates of corrective surgery. This patient had a Haller index of 3.90. The severity of this index, in the setting of PFTs consistent with restrictive pulmonary process, with an echocardiogram that reveals compression of the heart makes an indication of corrective surgery. A recent study revealed positive correlations between severity of sternal deformity and cardiac rotation, as well as clinically significant symptoms. ${ }^{2}$ The case was atypical in the sense that the symptoms of the patient did not correlate with the radiological findings.

\section{REFERENCES:}

1. Sidden CR, Katz ME, Swoveland BC, et al. Radiologic considerations in patients undergoing the Nuss procedure for correction of pectus excavatum. Pediatric Radiology 2001; 3:429-34.

2. Chu ZG, Yu JQ Yang ZG, et al. Correlation between sternal depression and cardiac rotation in pectus excavatum: Evaluation with helical CT. Am J Roentgenol 2010;195:76-80. 